\title{
Anionic Polyelectrolyte Hydrogels: Influence on Antibodies Production and Enzyme Activity
}

\author{
M.R. KOZAK ${ }^{1}$, A.V. OLIYNYK, M.M. MOSKVIN ${ }^{2}$, D.D. OSTAPIV, \\ N.E. MITINA' , O.S. ZAICHENKO' , V.V. VLIZLO' \\ ${ }^{1}$ Institute of Animal Biology, National Academy of Sciences of Ukraine, Lviv, Ukraine \\ ${ }^{2}$ Lviv Polytechnic National University, Lviv, Ukraine \\ E-mail: mariya_kozak@yahoo.com
}

Recombinant technologies are capable to produce specific molecules of DNA or protein that possess antigenic properties and are safe. However, individual antigen molecules are low-immunogenic, and therefore require conjugation with a compound possessing stronger adjuvant properties [3, 10]. Salts of aluminum, aqueous emulsions of squalene, viruses, virus-like nanoparticles, cationic liposomes, and others are used as adjuvants. A strong immune response in mice has been achieved with complete Freund's adjuvant, which includes lanolin, vaseline oil and killed mycobacterium tuberculosis [7]. However, it has got negative because of granulomas formation at the injection sites [6] and not suitable for the preparation of vaccines. The aluminum oxide hydrate and aluminum phosphate [2] only are currently authorized for use in most countries as adjuvants. Despite the fact that aluminum compounds are considered as safe, the occurrence of abscesses, eosinophils, granules and allergic manifestations at their application has been observed [1]. Therefore, the problem of expanding the assortment of such drugs continues to be topical and important.

The purpose of this study is to compare immunological effect of the created polymers using antigen - BSA model and to investigate their effect on the activity of enzymes of antioxidant defense, as well as ALT and AST.

Materials and methods. The PHG MG-4 and MG-8 have been synthesized via the dispersion polymerization of a monomer mixture in heptane (LobaChemie, India), azoisobutyronitrile (AIBN, Merck, Germany) has been used as initiator (5\% per monomers). Glycidyl methacrylate (GMA), butyl acrylate (BA), acrylic acid (AA), and triethylene glycol dimethacrylate (TGMDMA) have been used to obtain microsized PHG. Polymerization has been carried out in the flat bottom dilatometers or reactors at stirring for six hours at $70 \pm 0.2{ }^{\circ} \mathrm{C}$ pre-filled by argon. The kinetic of the reaction has been studied using dilatometric and gravimetric techniques. Polymer has been separated and washed to remove not reacted monomers. As a result of the polymerization a cross-linked PHG has been received (Fig. 1).

The content of the carboxyl groups has been determined by reverse acid-base titration followed by centrifugation and the selection of the liquid phase for analysis, the content of epoxy groups - by the reverse titration of the residues of chloric acid in $0.1 \mathrm{~N} \mathrm{NaOH}$. TEM images of PHG microparticles have been recorded on JEM-200A electron microscope at accelerating voltage of $200 \mathrm{kV}$. The hydrodynamic diameter and Z-potential of the PHG particles have been measured by dynamic light scattering on Zetasizer Nano (Malvern, UK) device using noninvasive inverse scattering technology at $25^{\circ} \mathrm{C}$. The concentration of samples has been $0.4 \mathrm{mg} / \mathrm{ml}$.

The in vivo study of action of PHG particles has been conducted on mice in accordance with the European Convention for the Protection of Vertebrate Animals (Strasbourg, 1986). Mice of 5 months of age have been divided into 4 groups ( 2 controls and 2 experimental), $\mathrm{n}=5$. Animals from the first control group have been injected subcutaneously of $40 \mu \mathrm{l}$ of $0.9 \%$ isotonic $\mathrm{NaCl}$ solution: and the second control group - $100 \mathrm{mg} / \mathrm{ml}$ BSA (AppliChem GmbH,

C Kozak M.R., Oliynyk A.V., Moskvin M.M. et al., 2017 
Germany): in the first experimental group - $40 \mu \mathrm{l}$ of MG-4 $(40 \mathrm{mg} / \mathrm{ml})$ and BSA $100 \mathrm{mg} / \mathrm{ml}$ in volumetric ratio $(1: 1)$; and in the second experimental group $40 \mathrm{\mu l}$ of MG-8 $(40 \mathrm{mg} / \mathrm{ml})$ and BSA $(100 \mathrm{mg} / \mathrm{ml})$ in a volume ratio $(1: 1)$. Immunization has been performed on following days: 1, 14 and 28. One week after the last injection, animals under anesthesia (chloroform, Sphere Sim, Ukraine) have been decapitated by cervical dislocation, and then blood has been taken.

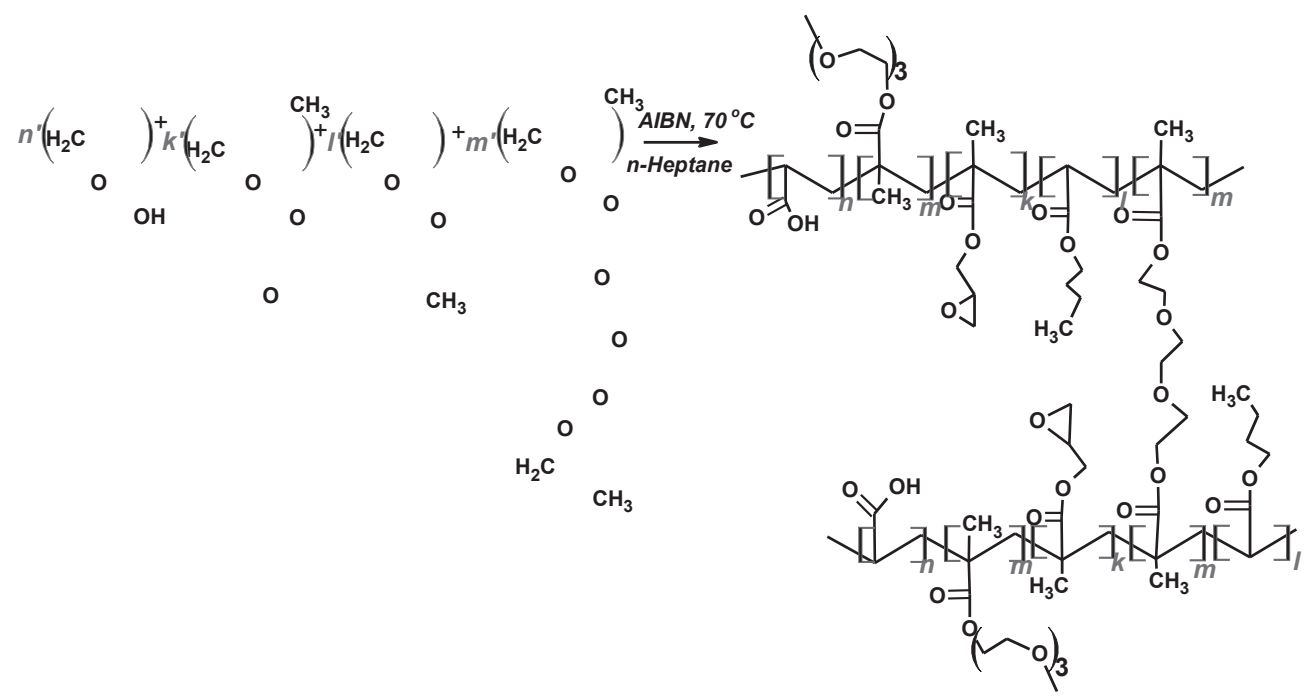

Fig.1. Scheme of cross-linked polymer formation.

Immunoglobulins have been isolated from blood serum of mice by three times deposition of a saturated solution of ammonium sulfate. ELISA method: $100 \mu \mathrm{l}$ $1 \%$ BSA solution has been adsorbed onto a plate (PAA, Austria) for 24 hours at $4{ }^{\circ} \mathrm{C}$; after that, they have been washed three times with buffer A $(0.2 \%$ BSA in buffered saline (PBS)) and added immunoglobulins isolated from blood serum of mice. The incubation has been for 2 hours at $37^{\circ} \mathrm{C}$; washed three times with buffer A and added second antibodies conjugated with alkaline phosphatase (anti-mouse (Sigma, Germany) in digestion (1:5000), incubated for 1 hour at $37^{\circ} \mathrm{C}$, washed three times with PFR-Tween-20, substrate for alkaline phosphatase, p-nitrophenylphosphate in diethanolamine (Filisit-Diagnostics, Ukraine), after 3 minutes, absorbance at $405 \mathrm{~nm}$ has been measured on an ELISA reader, STAT FAX (Awareness technology inc., USA).

The activity of enzymes superoxide dismutase (SOD), catalase, glutathioneperoxidase (GP) has been determined in liver homogenates. In particular, the activity of SOD has been evaluated using a quantitative analysis based on reduction of nitrotetrazolium by superoxide radicals (units per $1 \mathrm{mg}$ of protein). The activity of GP has been determined using a rate of oxidation of reduced glutathione and expressed in $\mu \mathrm{mol} / \mathrm{ml} \cdot \mathrm{min}$. The activity of catalase has been established by the ability of hydrogen peroxide to form a stable colored complex with molybdenum salts, expressed in $\mu \mathrm{mol} / \mathrm{ml} \cdot \min [5]$. The activity of alanine aminotransferase (ALT) and aspartate aminotransferase (AST) has been defined in the blood using commercial reagent kits (Felicity Diagnostics, Ukraine) according to the manufacturer's instructions. De Ritis coefficient has been calculated using a formula: coefficient de Ritis = activity of AST / activity of ALT.

Statistical calculations of results $(M \pm m)$ have been performed with Microsoft Excel 2007 computer program. The probability of differences has been determined by the Student's t-criterion.

Results and discussion. We have shown earlier the adjuvant properties of functional polymer coated polystyrene nanoparticles as well as anionic poly- 
electrolyte based on PHG microparticles $[3,4,8]$. Table 1 shows the composition of the monomer mixture and some characteristics of the obtained microgelic particles MG-4 and MG-8.

Table 1

Characteristics of functional microgelic particles

\begin{tabular}{|c|c|c|c|c|c|c|c|c|c|c|c|}
\hline \multirow[t]{3}{*}{$\begin{array}{c}\text { Sample } \\
\text { name }\end{array}$} & \multicolumn{4}{|c|}{$\begin{array}{l}\text { Composition of monomer } \\
\text { mixture during } \\
\text { synthesis, \% mol }\end{array}$} & \multicolumn{4}{|c|}{$\begin{array}{l}\text { Composition of the } \\
\text { obtained copolymer, } \\
\% \text { mol }\end{array}$} & \multirow{3}{*}{$\begin{array}{l}\text { Among. } \\
\text { particle } \\
\text { size, } \mu \mathrm{m} \\
\text { (from } \\
\text { TEM } \\
\text { image) }\end{array}$} & \multirow{3}{*}{$\begin{array}{c}\text { Hydro- } \\
\text { dynamic } \\
\text { diameter } \\
\text { of particles, } \\
\text { pm (from } \\
\text { the research } \\
\text { of the DLS) }\end{array}$} & \multirow[t]{3}{*}{\begin{tabular}{|}
$\mathrm{Z}-$ \\
potential \\
$\mathrm{mV}$
\end{tabular}} \\
\hline & GMA & BA & TEGDMA & $\mathbf{A A}$ & GMA & BA & TEGDMA & AA & & & \\
\hline & $k^{\prime}$ & $l^{\prime}$ & $m^{\prime}$ & $n^{\prime}$ & $k$ & $l$ & $m$ & $n$ & & & \\
\hline MG-4 & 10 & 15 & 1 & 74 & 14 & 12 & 4 & 70 & 0,49 & 0,64 & -49 \\
\hline MG-8 & 5 & 20 & 2 & 73 & 8 & 18 & 6 & 68 & 1,35 & 2,12 & -53 \\
\hline
\end{tabular}

Newly synthesized polymers PHG are the same in terms of quality chemical composition, but differ in quantitative ratios of monomer units. As a result, we have received the particles MG-8, which are by 2.8 times higher than MG-4 (table 1). The results of electron microscopy of the obtained polymers MG-4 and MG- 8 are presented in fig. 2 .

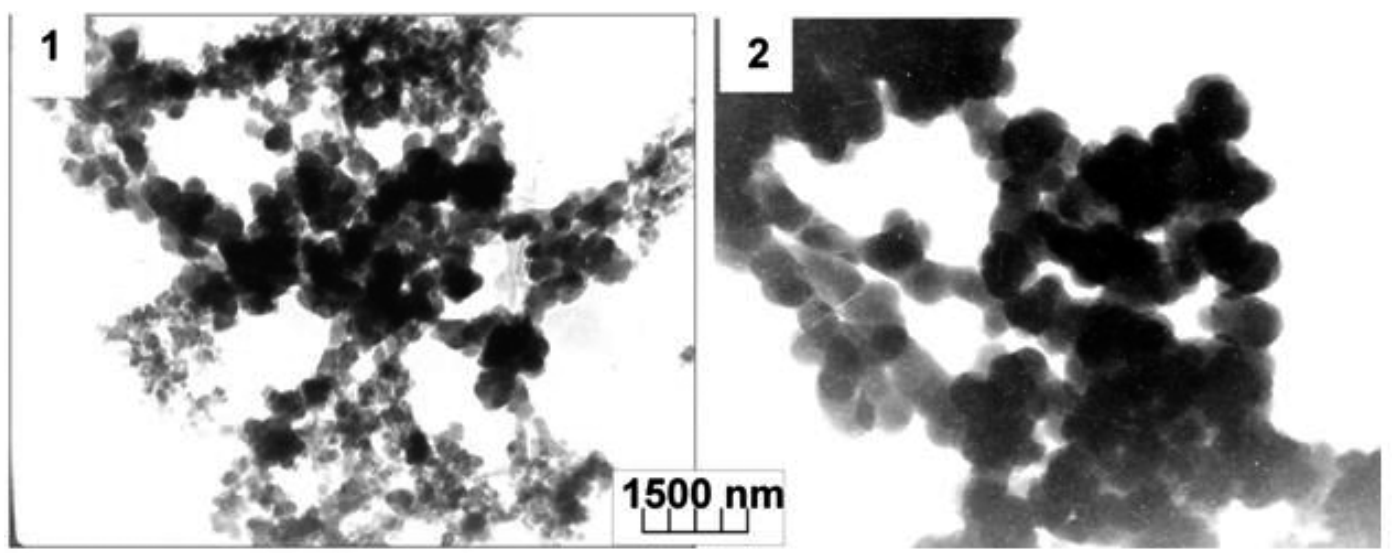

Fig. 2. Polymeric microgelic particles dispersed in water (electron microscopy). Note: 1 - MG-4; 2 - MG-8.

Mice have been injected subcutaneously three times at intervals of 2 weeks with aim to compare the adjuvant properties of the developed polymers. Applying affinity chromatography, immunoglobulins of $\mathrm{G}$ class have been obtained. Antibody titers have been determined using ELISA. It has been found that MG-4 polymer has better adjuvant properties than MG-8. This has been reflected in increase of anti-BSA antibody titers in $33.3 \%$, comparing to the action of MG-8, and up to 2-fold, in contrast with control animals (Fig. 3). Immunization with MG- 8 has been less effective, the antibody titer that is specific for BSA has increased in $35.3 \%$ compared to control.

Thus, the polymers contain epoxy groups, the activity of antioxidant enzymes - SOD, catalase and GP for their application has been studied. The decrease by 1.87 times of SOD activity in the liver of mice after immunization with MG-4 has been defined (Fig. 4).

The activity of catalase has been elevated by the action of both MG-4 and MG-8 in $20 \%$ (Fig. 5). The detected decrease in SOD activity could be caused by increase of $\mathrm{H}_{2} \mathrm{O}_{2}$ concentration - a product of catalyzed reaction, and at the same time its inhibitor, a substrate for catalase and GP [9]. Therefore, we have established the growth of catalase activity. A value of GP activity has been individual for all animals and stayed within the limits of physiological oscil- 
lations. In our previous studies, we have established the inhibition by MG-4 polymer of free radical oxidation processes [8]. We have assumed that the investigated MG-4 and MG-8 polymers have a positive effect on the enzymatic stage of antioxidant protection.

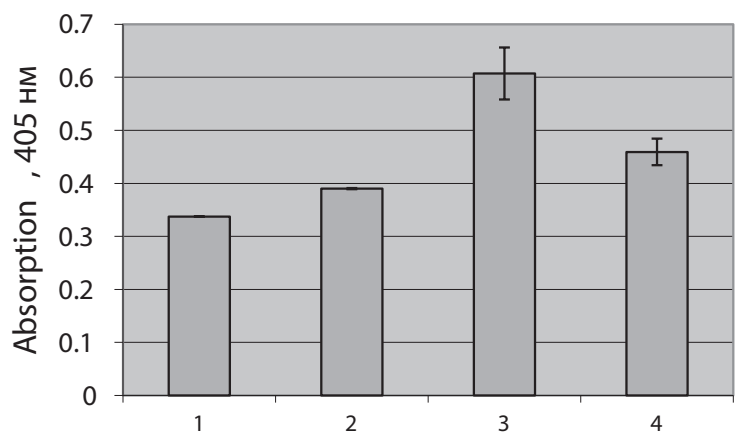

Groups of animals

Fig. 3. Titers of antibodies against BSA in blood serum of mice $(n=5)$.

Note: in this and the following figures: 1 - control group 1; 2 - control group 2 (animals, that have been subcutaneously injected with BSA only); 3 - experimental group 1 (animals, that have been injected with BSA containing MG-4 polymer); 4 - experimental group 2 (animals, that have been injected with BSA containing a polymer MG-8); ${ }^{*} p<0.05,{ }^{* *} p<0.01$.

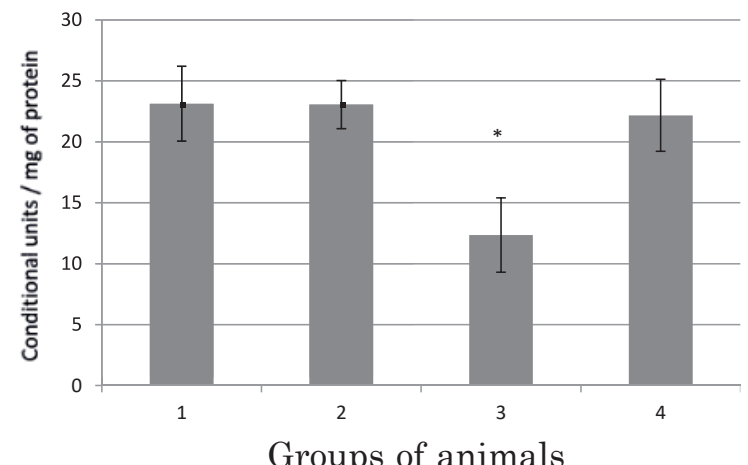

Fig. 4. SOD activity in liver of mice $(n=5)$

Note: ${ }^{*}-p<0.05$.

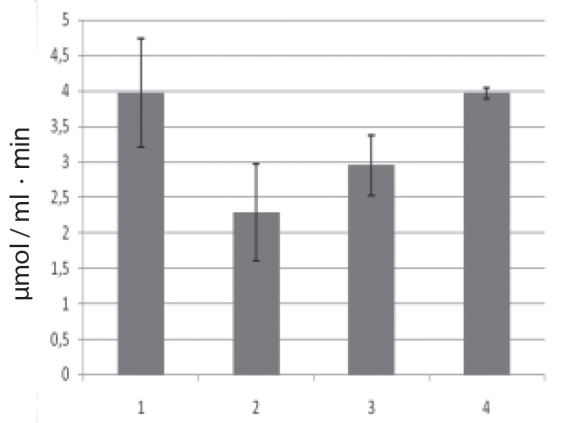

$a$

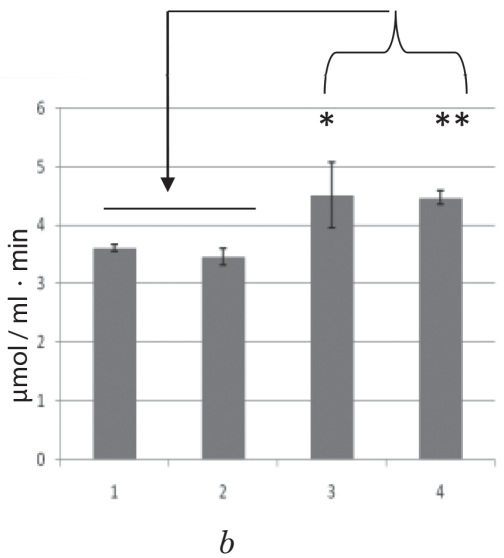

$b$

Groups of animals

Fig. 5. Activity of GP $(a)$ and catalase $(b)$ in liver of mice $(n=5)$ :

Note: ${ }^{*}-p<0.05,{ }^{* *}-p<0.01$ 
Transaminases are an important informative indicator of liver damage. Activity of ALT (Fig. 6) has increased by 1.46 times after the action of MG-4 $(p<0.05)$. ALT activity after the application of MG- 8 has corresponded to this indicator in the blood of control groups of mice. Also, AST activity has been higher in $29.3 \%(p<0.05)$ under the influence of MG-4, comparing to the mice that have been immunized only by BSA.
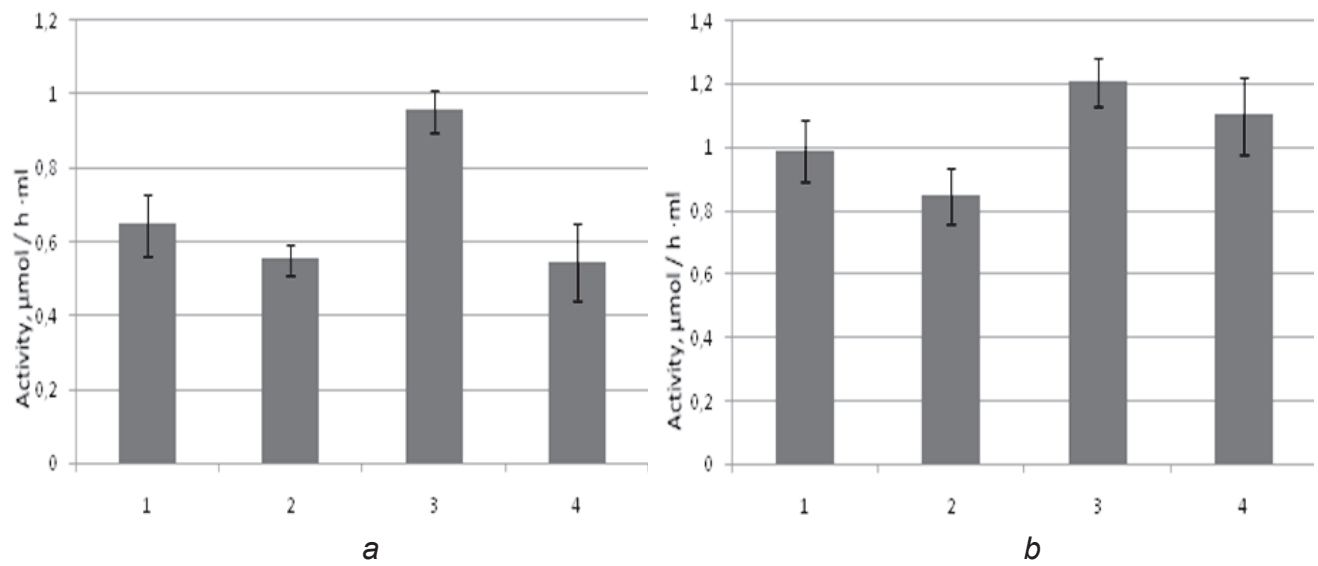

Fig. 6. Activity of ALT (a) and AST (b) in mice $(n=5)$. Note: ${ }^{*}-p<0.05$

An important prognostic indicator is not a value of transaminases activity, but - a factor of de Ritis, which is measured by the ratio of activity of AST to ALT. After the immunization of mice with MG-4, this indicator has been 1.33 that meets a norm. The application of polymer MG-8 has led to increase of de Ritis factor to 2 , that does not significantly exceed the norm.

Conclusions. As a result of the conducted studies, adjuvant properties have been found for the both PHG. The use of MG-4, which has smaller size, results in a higher antibody titers specific to the model antigen (BSA). Immunization with MG-4 and MG-8 leads to an increase of the activity of catalase, indicating the activation of the system of antioxidant protection of the organism. The detected minor changes in the activity of SOD and ALT after immunization with MG-4 may indicate a slight toxicity.

The article is recommended for publication by the Bioethics Commission: protocol No. 63 of the session of the Bioethical Examination Commission of the Institute of Animal Biology NAAS, September 19, 2017.

\section{Реколендовано до друку колісією з біоетики}

\section{REFERENCES}

1. Brunner R, Jensen-Jarolim E, Pali-Schöll I. The ABC of clinical and experimental adjuvants - a brief overwiew. Immunol Lett. 2010;1(128):29-35. 2. Chernysh N, Ma T. Micro and semimicro-methods of organic functional analysis: Per. From english. - Moscow: Chemistry. 1973;576 (in Russian). 3. Kit Yu, Bilyy R, Stoika R, Zaichenko A. Immunogenicity and adjuvant properties of novel biocompatible nanoparticles (Biocompatible nanomaterials: synthesis, characterization and applications, Chapter: Immunogenicity and Adjuvant Properties of Novel Biocompatible Nanoparticles). NY. Nova Sci. Publ., Inc., Hauppauge, Editors: Kumar S.A., Thiagarajan S., Wang S-F. 2011;209-223. 4. Kozak MR, Oliynyk AV, Zaichenko OS, Vlizlo VV. Adjuvant properties of polymer based on acrylic acid. Ukr. Biokhim. Zh. 2013; 85(3):69-73. doi: 10.15407/ubj85.03.069 (in Ukrainian). 5. Laboratory methods of research in biology, livestock and veterinary medicine. Reference book edited by Vlizlo VV., Lviv SPOL. 2012;761. 6. Lindblad $E B$. Aluminium adjuvants - in retrospect and prospect. Vaccine. 2004;22:3658-3668. 7. Nicholls $E$, Madera $L$, Hancock $R$. Immunomodulators as adjuvants for vaccines and antimicrobial therapy. Annals of the New York Academy of Sciences. 2010;1213:46-61. 8. Oliynyk AV, Kozak $M R$, Zaichenko OS, Vlizlo $V V$. Lipid hydroperoxides and TBA-active products in mouse organs at the action of adjuvants - polymer MG-4 and aluminum hydroxide. Journal of Animal Biology. 2012; 14(1-2):174-8. 9. Sybirna NO, Maevskaya OM, Barskaya ML. Research of certain 
biochemical indices under conditions of oxidative stress (Educational and methodical manual) Lviv. Publishing Centre at Lviv National University them. Ivan Franko. 2006:60. (in Ukrainian). 10. Zhu $M$, Wang R, Nie G. Applications of nanomaterials as vaccine adjuvants. Hum. Vaccin. Immunother. 2014;10(9):2761-2774.

Стаття надійшла до редколегії 30.08. 2017

\title{
RESEARCH ARTICLES
}

\section{Anionic Polyelectrolyte Hydrogels: Influence on Antibodies Production and Enzyme Activity}

\author{
M. KOZAK ${ }^{1}$, A. OLIYNYK ${ }^{1}$, M. MOSKVIN ${ }^{2}$, D. OSTAPIV ${ }^{1}$, N. MITINA ${ }^{2}$, \\ O. ZAICHENKO ${ }^{2}$, V.VLIZLO \\ ${ }^{1}$ Institute of Animal Biology, National Academy of Sciences of Ukraine, Lviv, Ukraine \\ ${ }^{2}$ Lviv Polytechnic National University, Lviv, Ukraine
}

Vaccination is the best biomedical approach to preventing from diseases. Proteins and peptides purified from microorganisms or synthesized chemically are weakly antigenic and need adjuvant to provide strong immune responses. Many substances with adjuvant properties have been discovered in different laboratories all over the world. However, only aluminum compounds continues to be traditional in clinical use. Although aluminum is regarded as safe, it has caused different effects, such as eosinophilia, abscesses, myofascilitis, granuloma formation and allergy, and influenced on the incidence of Alzheimer's disease. To avoid possible side effects of aluminum and to achieve long lasting immune responses, intensive research on development of new adjuvants has been conducted.

Cross-linked anionic polyelectrolyte hydrogels (PHG) have been synthesized via dispersion polymerization in non-polar organic media and their structures, functionality, hydrodynamic diameters have been determined. Newly synthesized polymers MG-4 and MG- 8 are the same in terms of quality chemical composition, but differ in quantitative ratios of monomer units. Aim of the study has been to evaluate immunological possibilities of PHG and its biological influence on mice. The adjuvant properties of PHG have been investigated using a model protein - bovine serum albumin (BSA). Mice 5 month old have been injected subcutaneously with PHG (MG-4 or MG-8) and BSA together, and with BSA alone, and with $0.9 \%$ isotonic $\mathrm{NaCl}$ solution. Immunization has been performed on the following days: 1,14 and 28. One week after the last injection antibodies have been isolated. The anti-BSA antibodies titers have been measured by immunoassay analysis. Possibilities of PHG MG-4 and MG-8 to produce of anti-BSA antibodies have been established. After subcutaneous immunization of mice with PHG of a lesser size MG-4, titers of specific to BSA antibodies have increased by $33.3 \%$ compared to a larger PHG MG-8. BSA alone have not stimulate sufficient antibody responses.

Because of the containing epoxy groups in polymers, the activity of antioxidant enzymes SOD, catalase and GP for their application have been studied. MG-4 has decreased SOD activity by $46.6 \%$ compared to the controls. Both hydrogels have raised catalase activity by $21.6 \%$. The value of GP activity has been individual for all animals and within the limits of physiological oscillations. Using MG-4 activity of ALT has been increased by 1.46 and AST by 1.22 times, however, the de Ritis factor, which is noted by the ratio of activity of AST to ALT, has been normal and amounted 1.33. The application of polymer MG-8 has caused an increase in the de Ritis factor to 2 .

Subcutaneous immunization with MG-4 and MG-8 leads to growth in the activity of catalase, indicating the activation of the system of antioxidant protection of the organism. The detected minor changes in the activity of SOD and ALT after immunization with MG-4 may indicate its slight toxicity. Adjuvant properties have been found for the both polymers. The use of MG-4, which has smaller size, results in higher antibody titers specific for the model antigen (BSA). The PHG with subcutaneous administration are permissible and suitable for further studies to establish safe and effective vaccines

Key words: polyelectrolyte hydrogels, adjuvants, immunoglobulins, enzymes, mice. 